\title{
Mathematical Modeling of Magnetic Fields of Actuators with Hape Memory Effect by a Combined Finite Element Method and Fundamental Solutions with Point Magnetic Moments
}

\author{
A.L. Balaban, Yu. A. Bakhvalov and V.V. Grechikhin \\ Platov South Russia State Polytechnic University (NPI), Novocherkassk, Russia
}

\begin{abstract}
The study is devoted to mathematical modeling of magnetic fields of positioning systems, the active elements of which are made of ferromagnets with shape memory effect. The development of effective systems of mathematical modeling of three-dimensional magnetic fields, necessary at the stage of design of positioning systems with ferromagnets with shape memory as well as the identification and diagnosis of such systems is relevant. In this study, one of the ways to increase the efficiency of modeling systems is considered. This is the application of a combined method combining the finite element grid method for field analysis in nonlinear calculation subdomains (ferromagnets) and the gridless method of fundamental solutions for calculating the field in linear subdomains (surrounding ferromagnet space and coils with current). The computational algorithm is developed on the basis of the mathematical model and the results of the solution of the test problem. Examples of its application are given. A distinctive feature of the proposed approach is the creation of a mathematical model of minimum dimension which provides a significant reduction in the calculation time. For the first time, vector point fictitious magnetic moments are used for the analysis of electromagnetic systems by the method of fundamental solutions. The new point sources of the field provide higher accuracy of calculation in comparison with magnetic dipoles. This allows solving the problems of designing positioning systems, performing their diagnostics in real time.
\end{abstract}

Key words: Method of fundamental solutions, finite element method, combined mathematical model, magnetic moment, magnetic dipole, computational algorithm, positioning systems, magnetic shape memory alloys

\section{INTRODUCTION}

Currently, intelligent materials are beginning to be widely used as active elements in the actuators of measuring and control systems including in precision positioning systems. Such materials include Magnetic Shape Memory Alloys (MSMA) which change the geometric dimensions under the influence of magnetic fields and mechanical forces and store the state (Vasil'ev et al., 2003; Wilson et al., 2007). The use of MSMA allows increasing the accuracy of conversion, to expand the range of displacements and simplify the construction of positioning systems (Asua et al., 2009; Hubert et al., 2012; Riccardi et al., 2012; Wang et al., 2005). Therefore, the development of effective systems for mathematical modeling of three-dimensional magnetic fields needed at the design stage of devices with MSMA is a relevant problem when multivariate calculations are carried out. Let us consider one of the ways to increase the efficiency of modeling systems. This is the application of a combined method combining the Finite Element grid
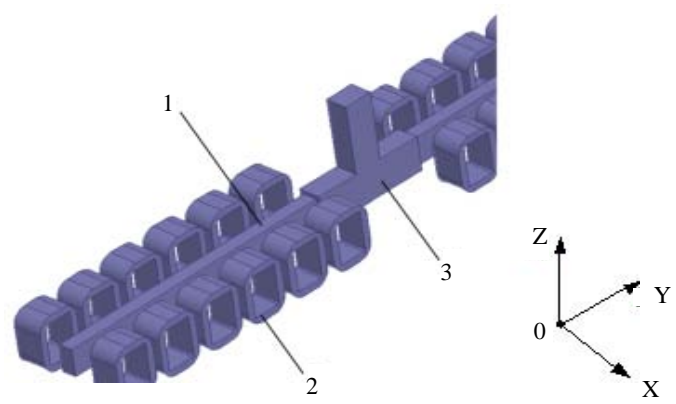

Fig. 1: General view of the actuator

Method (FEM) for field analysis in non-linear calculation subdomains (ferromagnets) and the gridless Method of Fundamental Solutions (MFS) for calculating the field in linear subdomains (surrounding ferromagnet space and coils with current).

The application of the combined method is shown on the example of modeling a three-dimensional magnetic field of a two-stroke actuator (Gorbatenko et al., 2015). Figure 1 shows the actuator under investigation

Corresponding Author: A.L. Balaban, Platov South Russia State Polytechnic University (NPI), Novocherkassk, Russia 
in which a distributed magnetizing system (1) is used containing $\mathrm{n}$ pairs of coils without ferromagnetic cores which allows to increasing the speed, reducing the mass and dimensions of the device as well as two active elements (2) made of MSMA and an actuator (3).

A combined finite element method and fundamental solutions using point charges were used earlier for the analysis of potential fields (Bakhvalov et al., 2015; Cao and Qin, 2015). The use of point magnetic dipoles in place of magnetic charges made it possible to increase the accuracy of the solutions but in a number of cases there was a numerical instability (Chen et al., 2008).

The use of point magnetic moments instead of dipoles in the performance of this research made it possible to increase the accuracy of the solutions while numerical instability was not observed.

\section{MATERIALS AND METHODS}

Problem formulation: It is required to develop a mathematical model of minimum dimension a combined method for calculating the field (FEM and MFS) using point magnetic moments and realizing its computational algorithm for the analysis and synthesis of three-dimensional magnetic fields of actuators with MSMA.

At the first stage of the research, the design and dimensions of the active elements and coils are assumed to be known as well as their magnetomotive force $\mathrm{iw}_{\mathrm{c}}$. It is necessary to calculate the magnetic field and also to investigate the dependence of the calculation error on the number of point sources of the field. At the second stage it is necessary to determine the size and magnetomotive force iw of the coils, under which the condition is met:

$$
\mathrm{H}_{z}^{+} \geq \mathrm{H}_{z}^{*}
$$

Where:

$\mathrm{H}_{\mathrm{z}}^{+}=$Calculated average value of the magnetic field strength in the middle section of the active element in the $\mathrm{x} 0 \mathrm{y}$ plane

$\mathrm{H}_{s}^{*}=$ Average value of the magnetic field strength known for this MSMA at which the size of the active element changes

Mathematical model: The mathematical model of the magnetic field of one pair of coils is constructed between which a part of the active element from the MSMA is located (Fig. 2). The results obtained with such a model can be easily extended to $\mathrm{n}$ pairs of coils. The stationary three-dimensional magnetic field of the problem is described by a system of Eq. 2 :

$$
\left\{\operatorname{rot} \overrightarrow{\mathrm{H}}=\vec{\delta} ; \operatorname{div} \overrightarrow{\mathrm{B}}=0 ; \mathrm{B}=\mathrm{B}(\mathrm{H}) \text { in } \mathrm{V}^{+} \overrightarrow{\mathrm{B}}=\mu_{0} \overrightarrow{\mathrm{H}} \text { in } \mathrm{V}^{-}\right.
$$

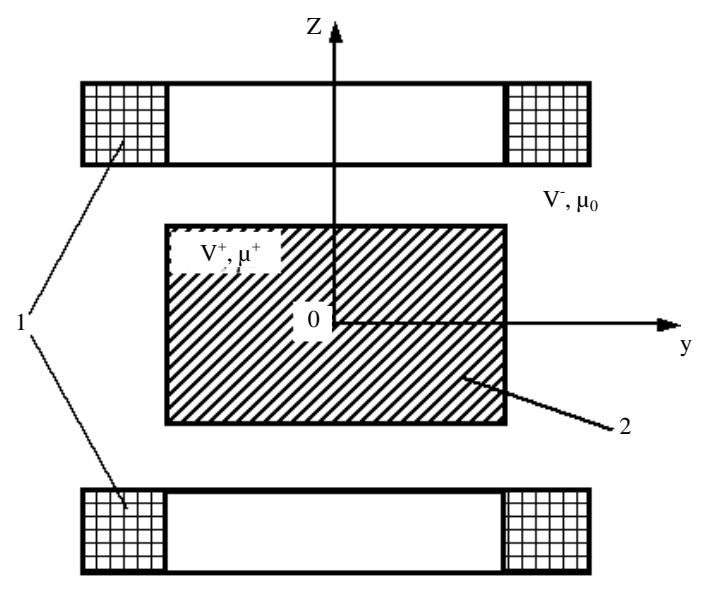

Fig. 2: Section of calculation area; 1) Magnetizing coil and 2) Active element from MSMA

with boundary conditions on media interfaces: $\mathrm{B}_{n}^{+}=\mathrm{B}_{n}^{;} ; \mathrm{H}_{\tau}^{+}=\mathrm{H}_{\tau}$. Here, $\mu_{0}$ magnetic constant; $\vec{\delta}$ current density in coils; $\mathrm{V}^{+}$subdomain occupied by an active element from the MSMA; $V^{-}$subdomain of the space surrounding the active element and filled with a linear medium with $\mu_{0}$ and coils; $\overrightarrow{\mathrm{B}}$ magnetic induction; $\overrightarrow{\mathrm{H}}$ magnetic field strength. The magnetic field strength is represented in $V^{-}$as a sum of two fields:

$$
\overrightarrow{\mathrm{H}}^{-}=\overrightarrow{\mathrm{H}}_{\delta}^{-}+\overrightarrow{\mathrm{H}}_{\mathrm{m}}^{-}
$$

Where:

$\overrightarrow{\mathrm{H}}_{\bar{\delta}}=$ Magnetic field strength, created by coil currents throughout the space $\mathrm{V}=\mathrm{V}^{+}+\mathrm{V}^{-}$when $\mathrm{a}$ ferromagnet is removed from it

$\vec{H}_{\mathrm{m}}=$ The intensity of the magnetic field in $\mathrm{V}^{\prime}$, created by the magnetization of the ferromagnet in the absence of current in the coils (Tozoni and Maergoyz, 1974)

The resultant field in $\mathrm{V}^{+}$is defined as the difference of close values this can lead to large errors when the term Eq. 3 is used. Therefore, in contrast to Tozoni and Maergoyz (1974), the resultant field $\overrightarrow{\mathrm{H}}_{\mathrm{n}}$ is defined in $\mathrm{V}^{+}$. The use of the expansion Eq. 3 makes it possible to use the scalar magnetic potential instead of the vector potential as the required variable and thereby reduce the dimension of the problem three times and also replace the system of Eq. 2 by the following three systems:

$$
\begin{gathered}
\operatorname{rot} \overrightarrow{\mathrm{H}}_{\delta}=\vec{\delta} ; \operatorname{div} \overrightarrow{\mathrm{B}}_{\delta}=\overrightarrow{\mathrm{B}}_{\delta}=0 ; \mu_{0} \overrightarrow{\mathrm{H}}_{\delta} \text { in V } \\
\overrightarrow{\mathrm{H}}^{+}=-\operatorname{grad} \varphi^{+} ; \mathrm{B}=\mathrm{B}(\mathrm{H}) ; \operatorname{div}\left(\mu_{0} \operatorname{grad} \varphi_{\mathrm{m}}^{+}\right)=0{\text { in } \mathrm{V}^{+}} \\
\overrightarrow{\mathrm{H}}_{\mathrm{m}}^{-}=-\operatorname{grad} \varphi_{\mathrm{m}}^{-} ; \overrightarrow{\mathrm{B}}_{\mathrm{m}}^{-}=\mu_{0} \overrightarrow{\mathrm{H}}_{\mathrm{m}} ; \operatorname{div}\left(\mu_{0} \operatorname{grad} \varphi_{\mathrm{m}}^{-}\right)=0 \operatorname{inV}^{-}
\end{gathered}
$$




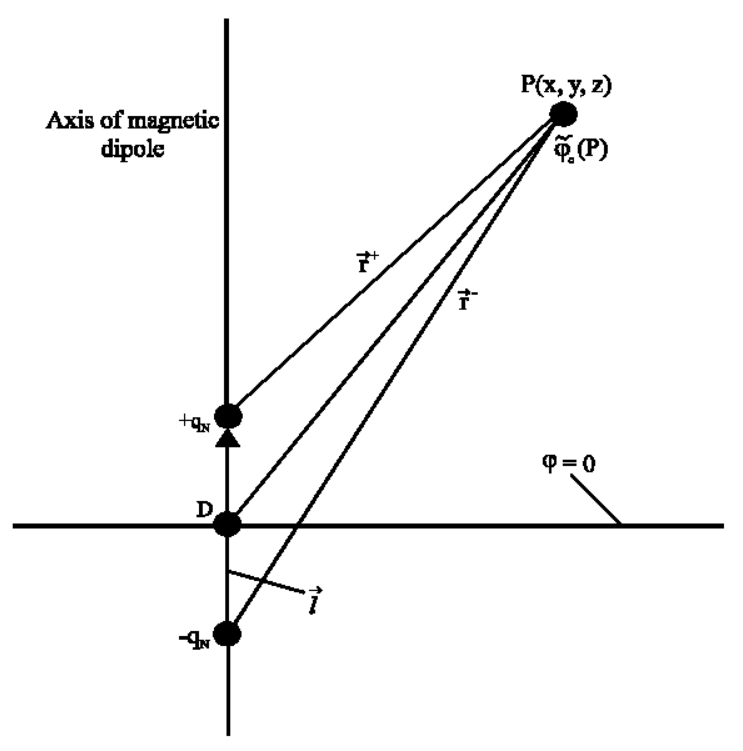

Fig. 3: Determination of the magnetic dipole potential

The solution of the system (4) is replaced by calculating $\overrightarrow{\mathrm{H}}_{\delta}$ by integrating over the volume of the coils $V_{c}=V_{c 1}+V_{c 2}$, using the formula obtained from the Biot-Savart-Laplace law:

$$
\overrightarrow{\mathrm{H}_{\delta}}(\mathrm{M})=\frac{1}{4 \pi} \iiint_{\mathrm{V}_{\mathrm{c}}} \frac{\left(\vec{\delta}\left(\mathrm{N}, \overrightarrow{\mathrm{e}_{\mathrm{r}}}\right)\right)}{\mathrm{r}_{\mathrm{NM}}^{2}} \mathrm{dV}_{\mathrm{N}}
$$

where, $\vec{\delta}=\left(\mathrm{iw}_{\mathrm{c}} / \mathrm{s}_{\mathrm{c}}\right) \mathrm{d} \overrightarrow{\mathrm{l}}$, iw $\mathrm{w}_{\mathrm{c}}$ the magnetomotive force created by the current $i$ in the coil with the number of turns $\mathrm{w}_{\mathrm{c}} ; \mathrm{S}_{\mathrm{c}}$ the cross-sectional area of the coil; $\overrightarrow{\mathrm{e}}_{\mathrm{r}}$ unit vector directed from point $\mathrm{N}$ to point $\mathrm{M}$ (Yavorskiy and Detlaf, 1974). The solution of the system (5) in a nonlinear medium $\mathrm{V}^{+}$is fulfilled by the FEM.

The solution of the system (6) in $\mathrm{V}^{-}$is performed by the MFS, the point sources of the magnetic field are located in $\mathrm{V}^{+}$. The following point sources can be used: scalar fictitious magnetic charges; vector fictitious magnetic dipoles; fictitious magnetic moments (Bakhvalov et al., 2016). The potential of a point magnetic charge $q_{m}(D)$ is determined at the point $P$ by the Eq. 8:

$$
\varphi_{c}(P)=\frac{q_{m}(D)}{4 \pi \mu_{0} r_{D P}}
$$

Let us consider the magnetic field of a dipole. If place two fictitious magnetic charges $-\mathrm{q}_{\mathrm{m}}$ and $+\mathrm{q}_{\mathrm{m}}$ the distance between which 1, near the point D (Fig. 3) then from the Eq. 8 for determining the field potential at the point $\mathrm{P}$ is pass to the formula (Shimoni, 1964):

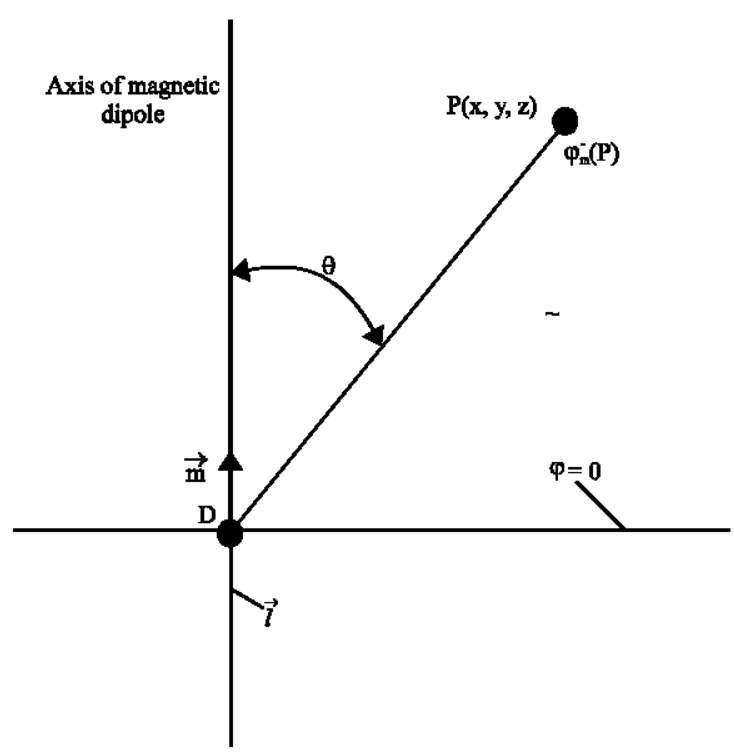

Fig. 4: Determination of the potential of the point magnetic moment

$$
\varphi_{c}(P)=\frac{\mathrm{q}_{\mathrm{m}}(\mathrm{D})}{4 \pi \mu_{0}}\left(\frac{1}{|\overrightarrow{\mathrm{r}}+1|}-\frac{1}{|\overrightarrow{\mathrm{r}}|}\right) \approx-\frac{\mathrm{q}_{\mathrm{m}} \overrightarrow{1}}{4 \pi \mu_{0}} \operatorname{grad}_{\mathrm{P}} \frac{1}{\mathrm{r}_{\mathrm{DP}}}
$$

The vector quantity is $\overrightarrow{\tilde{m}}=\mathrm{q}_{m} \overrightarrow{1}$ called the magnetic moment. If $\vec{i} \rightarrow 0, q_{m} \rightarrow \infty$, then $\overrightarrow{\tilde{m}}$ is tends to a finite limit $\vec{m}$ and the potential to the value $\varphi_{\mathrm{m}}(\mathrm{P})$ :

$$
\varphi_{c}(\mathrm{D}) \rightarrow \varphi_{\mathrm{m}}^{-}(\mathrm{P})=-\frac{\overrightarrow{\mathrm{m}}}{4 \pi \mu_{0}} \operatorname{grad}_{\mathrm{P}} \frac{1}{\mathrm{r}_{\mathrm{DP}}}
$$

or

$$
\varphi_{\mathrm{m}}(\mathrm{P})=\frac{1}{4 \pi \mu_{0}} \frac{\mathrm{m} \cos \theta}{\mathrm{r}^{2}{ }_{\mathrm{DP}}}
$$

That is to the potential of the point magnetic moment (Fig. 4). The calculation error is reduced by the Eq. 9 with $1 \rightarrow 0$ but in this case the computational error will increase that is the error of the difference of close values. Therefore, the proposed combined method of calculating the field uses Eq. 10. As follows from (10), the potential of a point magnetic moment has axial symmetry in contrast to the potential of a point charge with spherical symmetry. The potentials of the magnetic moment and magnetic dipole are zero at points lying in a plane perpendicular to the axis of the moment (dipole) and passing through the point $\mathrm{D}$.

Thus, point magnetic moments and magnetic dipoles are convenient to use in those cases when the system under investigation has a plane of symmetry, the potential of which can be assumed to be zero. The problem under consideration satisfies this requirement. 


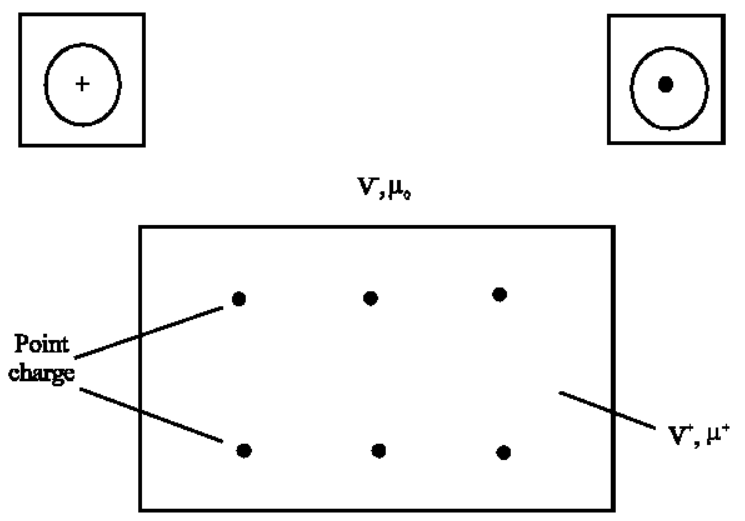

Fig. 5: Location of point charges in an asymmetric electromagnetic system

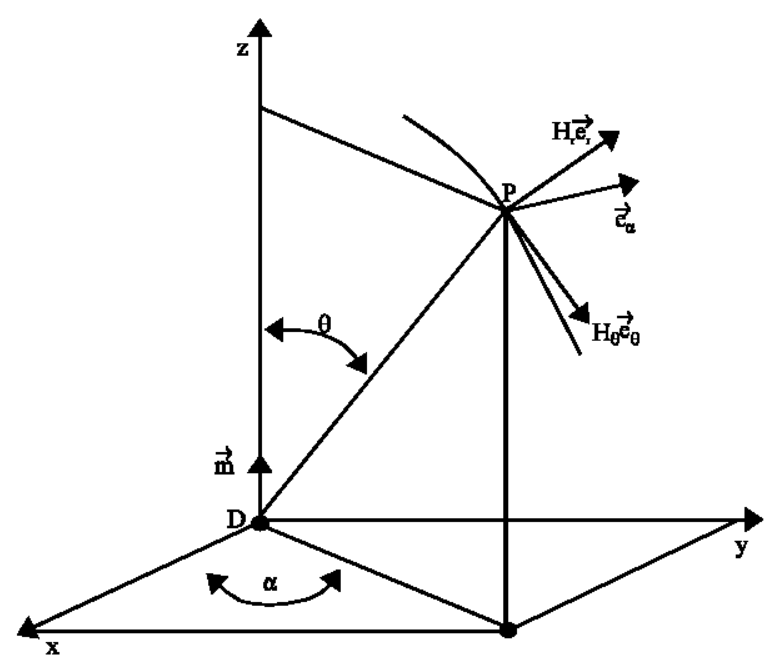

Fig. 6: Determination of the magnetic field strengths of a point magnetic moment

Point fictitious magnetic sources (scalar and vector) can be used in the study of both symmetric and non-symmetric systems (Fig. 5). In the case of an asymmetric system, the number of unknown quantities doubles. The strength of a point magnetic moment in a spherical coordinate system is determined by the following equation (Fig. 6):

$$
\begin{aligned}
& \mathrm{H}_{\mathrm{mr}}^{-}=-\frac{\partial \varphi}{\partial \mathrm{r}}=\frac{1}{2 \pi \mu_{0}} \frac{\mathrm{m} \cos \theta}{\mathrm{r}_{\mathrm{DP}}^{3}} \\
& \mathrm{H}_{\mathrm{m} \theta}^{-}=-\frac{1 \partial \varphi}{\mathrm{r} \partial \varphi}=\frac{1}{4 \pi \mu_{0}} \frac{\mathrm{m} \sin \theta}{\mathrm{r}_{\mathrm{DP}}^{3}}
\end{aligned}
$$

$\mathrm{H}_{\max }=0$ because of the axial symmetry of the field $\vec{m}$. Further, it is necessary to use $\mathrm{z}$ component of the magnetic field strength which we will determine by Eq. 11:

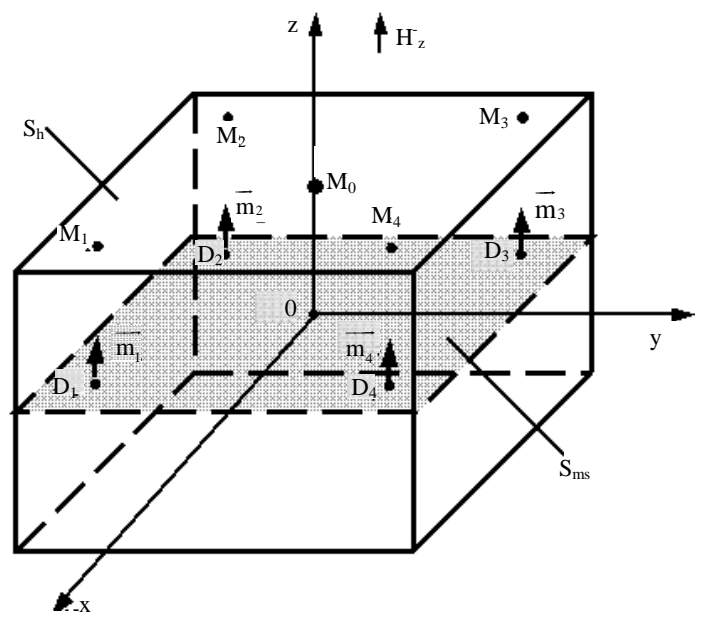

Fig. 7: Placement of the coordinate system and point sources in the active element

$$
\mathrm{H}_{\mathrm{mz}}^{-}=\mathrm{H}_{\mathrm{mr}}^{-} \cos \theta-\mathrm{H}_{\mathrm{m} \theta}^{-} \sin \theta=\frac{3 \cos ^{2} \theta-1}{\mathrm{r}_{\mathrm{DP}}^{3}} \mathrm{~m}^{\prime}
$$

where, $\mathrm{m}^{\prime}=\mathrm{m} /\left(4 \pi \mu_{0}\right)$. If there are $\mathrm{N}$ point magnetic moments then the values $\varphi_{\mathrm{m}}(\mathrm{P})$ and $\mathrm{H}_{\mathrm{ra}}(\mathrm{P})$ in $\mathrm{V}^{-}$are determined by the Eq. 12 and 13 :

$$
\begin{gathered}
\varphi_{m}(P)=\sum_{j=0}^{N-1} \frac{m_{j}^{\prime} \cos \theta_{j}}{r_{D_{j} P}^{2}} \\
H_{m z}^{-}(P)=\sum_{j=0}^{N-1} \frac{m_{j}^{\prime} \cos \theta_{j}-1}{r_{D_{j} P}^{3}}
\end{gathered}
$$

On the basis of (6) a system of equations is constructed with the use of point magnetic moments. The beginning of a Cartesian coordinate system is located in the center of the active element (Fig. 7). Taking into account the symmetry of the electromagnetic system under consideration with respect to the $\mathrm{x} 0 \mathrm{y}$ plane, the solution of the problem is sought in the region $\mathrm{z} \geq 0$. Point magnetic moments (the number $\mathrm{N}$ ) are located on the middle section $\mathrm{S}_{\mathrm{ms}}$ of the region $\mathrm{V}^{+}$, lying in the $\mathrm{x} 0 \mathrm{y}$ plane. On the upper boundary $\mathrm{S}_{\mathrm{h}}$ of the active element, $\mathrm{N}$ collocation points $\mathrm{M}_{\mathrm{i}}$ are located in which the following relations which follow from the initial boundary conditions $\left(\overrightarrow{\mathrm{n}}=\overrightarrow{\mathrm{e}}_{\mathbf{z}}\right)$ :

$$
\begin{aligned}
& \varphi^{+}\left(\mathrm{M}_{\mathrm{i}}\right)=\varphi_{\delta}^{-}\left(\mathrm{M}_{\mathrm{i}}\right)+\varphi_{\mathrm{m}}^{-}\left(\mathrm{M}_{\mathrm{i}}\right) \\
& \mu^{+} \mathrm{H}_{\mathrm{mz}}^{+}\left(\mathrm{M}_{\mathrm{i}}\right)=\mu_{0} \mathrm{H}_{\delta z}^{-}\left(\mathrm{M}_{\mathrm{i}}\right)+\mu_{0} \mathrm{H}_{\mathrm{mz}}^{-}\left(\mathrm{M}_{\mathrm{i}}\right), \mathrm{i}=0,1, \ldots, \mathrm{N}-1
\end{aligned}
$$

where, $\varphi_{m}\left(M_{i}\right)$ is determined by the Eq. $12 ; H_{m z}\left(M_{i}\right)$ is determined by the Eq. 13; $\quad \mathrm{H}_{\mathrm{ma}}^{+}\left(\mathrm{M}_{\mathrm{i}}\right)=-\partial \varphi^{+}\left(\mathrm{M}_{\mathrm{i}}\right) / \partial z$; 
$H_{8 z}\left(M_{i}\right)=-\partial \varphi_{s}\left(M_{i}\right) / \delta z$ is determined by the Eq. 7 the field potential of the coils with current is determined by the Eq. 15:

$$
\varphi_{\delta}\left(M_{i}\right)=\int_{0}^{z_{i}} H_{\delta z}^{-}(z) d z
$$

The system of Eq. 14 contains $2 \mathrm{~N}$ equations and $3 \mathrm{~N}$ unknowns $\left\langle\mathrm{m}_{1}, \Phi^{+}\left(\mathrm{M}_{2}\right), \mathrm{H}_{2}^{+}\left(\mathrm{M}_{4}\right), \mathrm{i}=0, \ldots, \ldots, \mathrm{N}_{1}\right)$. In addition, the $\mathrm{N}$ equations connecting $\varphi^{+}\left(\mathrm{M}_{\mathrm{i}}\right)$ and $\mathrm{H}_{z}^{+}\left(\mathrm{M}_{\mathrm{i}}\right)$ is obtained in the solution in the region $\mathrm{V}^{+}$of the system (5) by the FEM.

Computational algorithm: The geometric dimensions of the active element are assumed to be known: width $\mathrm{A}_{e}$ and length $\mathrm{B}_{\mathrm{e}}$ (dimensions along the axes $0 \mathrm{x}$ and $0 \mathrm{y}$ ); thickness $\mathrm{H}_{e}$ (size along the $\mathrm{Oz}$ axis), the geometric dimensions of the coil (width $\mathrm{A}_{c}$, length $\mathrm{B}_{c}$, thickness $\mathrm{H}_{0}$ 。 wire winding thickness $\mathrm{C}_{c}$ ) and magnetomotive force $\mathrm{iw}_{\mathrm{c}}$ produced by currents in the coils.

Note that the potential $\varphi^{+}\left(\mathrm{M}_{i}\right)$ is $0.2-0.3 \%$ of $\varphi_{\bar{\delta}}\left(\mathrm{M}_{\mathrm{i}}\right)$ and $\varphi\left(\mathrm{M}_{\mathrm{i}}\right)$. The algorithm for solving system (12) consists of the following stages: the choice of the position of point magnetic moments $\left(D_{j}\right)$ and collocation points $M_{i}$ where, $i=0,1, \ldots, N-1 ; j=0,1, \ldots, N-1$ and the formation of arrays of their coordinates. Calculation at the collocation points $\mathrm{M}_{\mathrm{i}} \mathrm{H}_{\overline{8}}\left(\mathrm{M}_{\mathrm{i}}\right)$ and $\varphi_{8}\left(\mathrm{M}_{\mathrm{i}}\right)$ using Eq. 7 and 15 . It is assumed that $\varphi^{+}\left(\mathrm{M}_{\mathrm{i}}\right) \approx 0$. Solving the first $\mathrm{N}$ equations of system Eq. 12, it is found $m_{j}, j=0,1, \ldots, N-1$. Solving the second $\mathrm{N}$ equations of system (5) it is found $\mathrm{H}_{z}^{+}\left(\mathrm{M}_{\mathrm{i}}\right), \mathrm{i}=0,1, \ldots, \mathrm{N}-1$. Solution of the boundary value problem by the FEM, system (6) in $\mathrm{V}^{+}$using the following boundary conditions: on the section $\mathrm{S}_{\mathrm{ms}}$ lying in the $\mathrm{x} 0 \mathrm{y}$ plane $\phi=0$ on the side faces of the active element $\partial \varphi / \partial \mathrm{n}=0$ on the upper face $\mathrm{S}_{\mathrm{h}}-\partial \varphi / \partial \mathrm{n}=\partial \varphi / \partial z=-\mathrm{H}_{z}^{+}\left(\mathrm{M}_{\mathrm{i}}\right)$. The FEM is found $\phi^{+}\left(\mathrm{M}_{\mathrm{i}}\right)$ using the $\mathrm{B}(\mathrm{H})$ dependence of a ferromagnetic material or a specified value $\mu^{+}$. Refinement of the value $\phi^{+}\left(\mathrm{M}_{\mathrm{i}}\right)$ and $\mathrm{m}_{\mathrm{i}}^{\prime}$.

\section{RESULTS AND DISCUSSION}

The system for research is selected with the following parameters: $\mathrm{A}_{\mathrm{e}}=\mathrm{B}_{\mathrm{e}}=\mathrm{A}_{\mathrm{c}}=\mathrm{B}_{\mathrm{c}}=2.10^{-3} \mathrm{~m} ; \mathrm{H}_{\mathrm{e}}$ $=1.10^{-3} \mathrm{~m} ; \mathrm{H}_{\mathrm{c}}=2.10^{-3} \mathrm{~m} ; \mathrm{C}_{\mathrm{c}}=0.5 \cdot 10^{-3} \mathrm{~m} ; \mathrm{a}=\mathrm{b}=0.2 .10^{-3}$ $\mathrm{m} ; \mu^{+}=10^{3} \mu_{0} ; i \mathrm{w}_{\mathrm{c}}=10^{3} \mathrm{~A}$.

The initial problem is solved by the FEM for estimating the error of the combined method. The coils and the active element in the center of the parallelepiped with sides $0.5 \times 0.25 \times 0.25 \mathrm{~m}$ for this purpose 79221 tetrahedron is filled. The value of the magnetic potential at the artificial boundary is $\vec{A}=0$. The values of $\varphi_{\delta}\left(\mathrm{M}_{\mathrm{i}}\right), \varphi^{+}\left(\mathrm{M}_{\mathrm{i}}\right), \mathrm{H}_{\bar{\delta} z}\left(\mathrm{M}_{\mathrm{i}}\right), \mathrm{H}_{z}^{+}\left(\mathrm{M}_{\mathrm{i}}\right)$ are determined at the points of collocation by the FEM. In this case, a finite-element

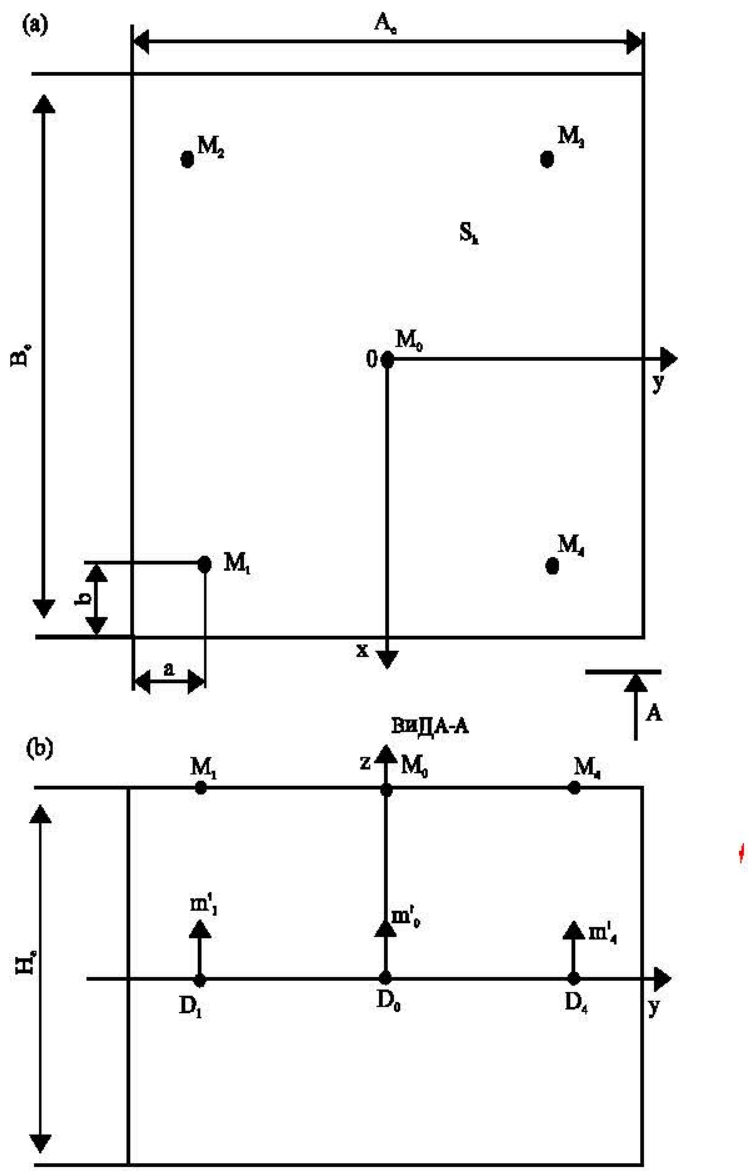

Fig. 8: For example 1: a) The upper bound of the active element $S_{h}$ with the points of collocations $M$ and b) The arrangement of point magnetic moments $m$

grid containing 39610 tetrahedra and 53574 nodes was used to calculate the field in the region $z \geq 0$. Solution of the problem by a combined method (FEM and MFS) is shown below.

Example 1: $N=5$ collocation points are selected (Fig. 8). The same number of point magnetic sources are placed on the plane $S_{m s}$ of the active element at points with coordinates $\mathrm{z}_{\mathrm{i}}=0, \mathrm{x}_{\mathrm{i}}$ and $\mathrm{y}_{\mathrm{i}}$ coincide with the corresponding coordinates of the collocation points. Because of the symmetry of the positions of the points there are $m_{1}^{\prime}=m_{2}^{\prime}=m_{3}^{\prime}=m_{4}^{\prime}$. Thus, in this example there are two unknown magnetic moments $\mathrm{m}_{0}^{\prime}$ and $\mathrm{m}_{1}^{\prime}$ as well $\varphi^{+}\left(\mathrm{M}_{0}\right), \quad \varphi^{+}\left(\mathrm{M}_{1}\right), \quad \mathrm{H}_{z}^{+}\left(\mathrm{M}_{0}\right), \mathrm{H}_{z}^{+}\left(\mathrm{M}_{1}\right)$. The results of the calculation are summarized in Table 1. The Standard Deviation (RMSD) of the field calculation results developed by the combined method of MFS and FEM $\left(\mathrm{H}_{\mathrm{z}}^{+}\right)$from the results obtained by FEM $\left(\mathrm{H}_{z i}^{+}\right)$are calculated by the formula: 
Table 1: The results of calculations for $\mathrm{N}=5$ Calculation by the combined method (MFS and FEM)

\begin{tabular}{lcccccc} 
Point No. (i) & $\mathrm{H}_{\delta}(\mathrm{A} / \mathrm{m})$ & $\phi_{\delta}(\mathrm{A})$ & $\mathrm{H}_{z}^{+}(\mathrm{A} / \mathrm{m})$ & $\phi^{+}(\mathrm{A})$ & $\begin{array}{c}\text { Calculation by the FEM } \\
\mathrm{H}_{\alpha}^{+}(\mathrm{A} / \mathrm{m})\end{array}$ & $\begin{array}{c}\text { Relative error } \\
\delta\left(\mathrm{H}_{z}^{+}\right)(\%)\end{array}$ \\
\hline 0 & 179866.22 & 82.90 & 447.44 & $1.75 \times 10^{-5}$ & 266.25 & 68.06 \\
1 & 125031.71 & 55.95 & 308.78 & $1.21 \times 10^{-5}$ & 215.99 & 42.96 \\
\hline
\end{tabular}

Table 2: The results of calculations for $\mathrm{N}=9$ Calculation by the combined method (MFS and FEM)

\begin{tabular}{lllcccc} 
Point No. (i) & $\mathrm{H}_{\delta}(\mathrm{A} / \mathrm{m})$ & $\phi_{\delta}(\mathrm{A})$ & $\mathrm{H}_{z}^{+}(\mathrm{A} / \mathrm{m})$ & $\phi^{+}(\mathrm{A})$ & $\begin{array}{c}\text { Calculation by the FEM } \\
\mathrm{H}^{+}(\mathrm{A} / \mathrm{m})\end{array}$ & $\begin{array}{c}\text { Relative error } \\
\delta\left(\mathrm{H}_{z}^{+}\right)(\%)\end{array}$ \\
\hline 0 & 179866.22 & 82.90 & 355.47 & $1.21 \times 10^{5}$ & 266.25 & 33.51 \\
1 & 125031.71 & 55.95 & 257.16 & $9.08 \times 10^{6}$ & 215.99 & 19.06 \\
2 & 150115.04 & 68.04 & 302.77 & $1.05 \times 10^{5}$ & 240.92 & 25.68 \\
\hline
\end{tabular}

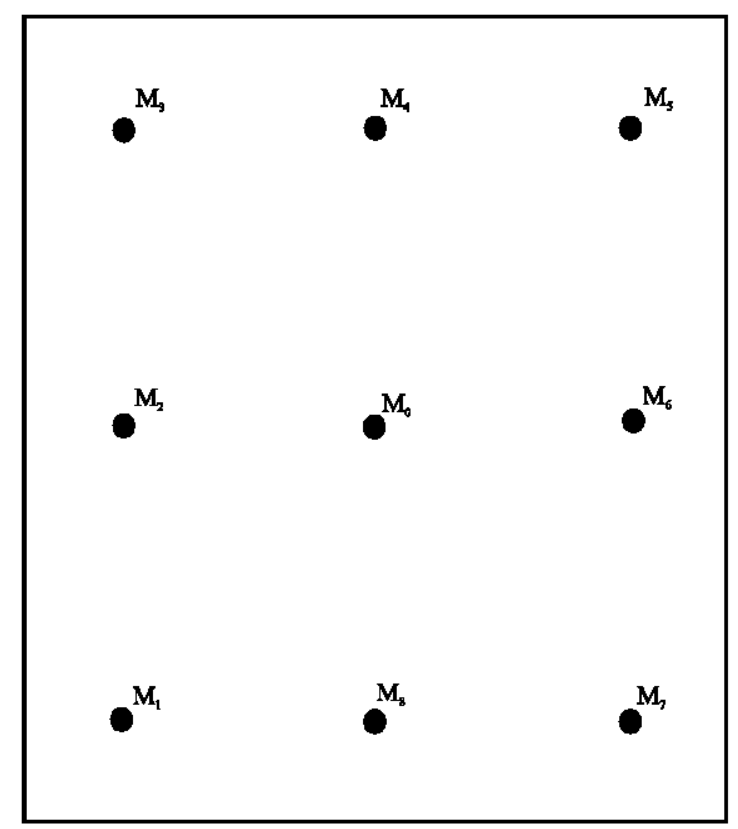

Fig. 9: Arrangement of collocation points for $\mathrm{N}=9$

$$
\operatorname{RMSD}=\sqrt{\sum_{i=0}^{\mathrm{N}-1}\left(\mathrm{H}_{z \mathrm{i}}^{+}-\mathrm{H}_{z i}^{+}(\mathrm{KM})\right)^{2} / \mathrm{N}}
$$

For $\mathrm{N}=5 \mathrm{RMSD}$ is $124.5 \mathrm{~A} / \mathrm{m}$.

Example 2: $N=9$ collocation points (Fig. 9) are placed on the plane $\mathrm{S}_{\mathrm{h}}$. Due to the symmetry of their position there are three unknown moments $\mathrm{m}_{0}^{\prime} ; \mathrm{m}_{1}^{\prime} ; \mathrm{m}_{2}^{\prime}$ as well as unknowns $\mathrm{H}_{z}^{+}\left(\mathrm{M}_{\mathrm{i}}\right)$ and $\varphi^{+}\left(\mathrm{M}_{\mathrm{i}}\right), \mathrm{i}=0,1,2$. The system of equations is compiled in the same way as in example 1 . The results are summarized in Table 2. For $\mathrm{N}=9 \mathrm{RMSD}$ is $57.78 \mathrm{~A} / \mathrm{m}$.

Example 3: $N=13$ collocation points (Fig. 10) are placed on the plane $S_{h}$. Due to the symmetry of their position, there are four unknown moments $\mathbf{m}_{0}^{\prime} ; \mathbf{m}_{1}^{\prime} ; \mathbf{m}_{2}^{\prime} ; \mathbf{m}_{3}^{\prime}$ as well as unknowns $\mathrm{H}_{z}^{+}\left(\mathrm{M}_{\mathrm{i}}\right)$ and $\varphi^{+}\left(\mathrm{M}_{\mathrm{i}}\right), \mathrm{i}=0,1,2$. For $\mathrm{N}=13$ RMSD is $25.90 \mathrm{~A} / \mathrm{m}$.

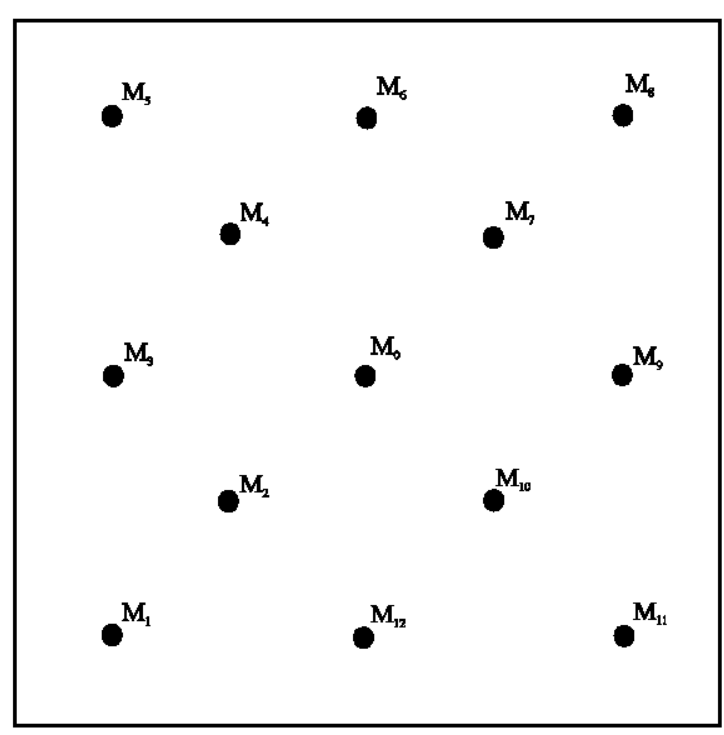

Fig. 10: Arrangement of collocation points for $\mathrm{N}=13$

Example 4: $N=25$ collocation points (Fig. 11) are placed on the plane $\mathrm{S}_{\mathrm{h}}$. Due to the symmetry of their position, there are six unknown moments $\mathrm{m}_{0}^{\prime} ; \mathrm{m}_{1}^{\prime} ; \mathrm{m}_{2}^{\prime} ; \mathrm{m}_{3}^{\prime} ; \mathrm{m}_{4}^{\prime} ; \mathrm{m}_{5}^{\prime}$ as well as unknowns $H_{z}^{+}\left(M_{i}\right)$ and $\varphi^{+}\left(M_{i}\right), i=0,1,2$. For $N=25$ RMSD is $2.02 \mathrm{~A} / \mathrm{m}$.

In relative values, the dependence of RMSD on the number of field sources, namely magnetic moments (the number of collocation points $\mathrm{N}$ ) for the considered examples is shown in Fig. 12. The magnetic field is calculated at any point of $V^{-}$using Eq. 2, 12 and 13 after determining the moduli of magnetic moments.

The field in $\mathrm{V}^{+}$is determined by the FEM. In this case, a finite-element grid with the number of tetrahedra 1817 and 3145 knots is used in region $\mathrm{z} \geq 0$ (Table 3 and 4). The magnetomotive force $\mathrm{iw}_{\mathrm{c}}$ and the dimensions of the coils are determined in the second stage of the investigation, solving the inverse problem (Bahvalov et al., 2014). Initial values of the sizes of coils and $\mathrm{iw}_{\mathrm{c}}^{(0)}$ are selected. The objective function of the task is compiled on the basis of (1): 
Table 3: The results of calculations for $\mathrm{N}=13$

Calculation by the combined method (MFS and FEM)

\begin{tabular}{|c|c|c|c|c|c|c|}
\hline Point No. (i) & $\mathrm{H}_{8}^{-}(\mathrm{A} / \mathrm{m})$ & $\phi_{8}(\mathrm{~A})$ & $\mathrm{H}_{\mathrm{z}}^{+}(\mathrm{A} / \mathrm{m})$ & $\phi^{+}(\mathrm{A})$ & $\begin{array}{c}\text { Calculation by the FEM } \\
\qquad \mathrm{H}^{+}(\mathrm{A} / \mathrm{m})\end{array}$ & $\begin{array}{c}\text { Relative error } \\
\delta\left(\mathrm{H}_{z}^{+}\right)(\%)\end{array}$ \\
\hline 0 & 179866.22 & 82.90 & 291.56 & $6.74 \times 10^{-6}$ & 266.25 & 9.51 \\
\hline 1 & 125031.71 & 55.95 & 241.36 & $7.83 \times 10^{-6}$ & 215.99 & 11.75 \\
\hline 2 & 168992.59 & 76.11 & 278.15 & $6.21 \times 10^{-6}$ & 256.46 & 8.46 \\
\hline 3 & 150115.04 & 68.04 & 270.99 & $7.89 \times 10^{-6}$ & 240.92 & 12.48 \\
\hline
\end{tabular}

Table 4: The results of calculations for $\mathrm{N}=25$

\begin{tabular}{|c|c|c|c|c|c|c|}
\hline \multirow[b]{2}{*}{ Point No. (i) } & \multicolumn{6}{|c|}{ Calculation by the combined method (MFS and FEM) } \\
\hline & $\mathrm{H}_{8},(\mathrm{~A} / \mathrm{m})$ & $\phi_{8}^{-},(\mathrm{A})$ & $\mathrm{H}_{\mathrm{z}}^{+},(\mathrm{A} / \mathrm{m})$ & $\phi^{+},(\mathrm{A})$ & $\begin{array}{c}\text { Calculation by the FEM } \\
\qquad \mathrm{H}^{+},(\mathrm{A} / \mathrm{m})\end{array}$ & $\begin{array}{l}\text { Relative error } \\
\delta\left(\mathrm{H}_{\mathrm{z}}^{+}\right)(\%)\end{array}$ \\
\hline 0 & 179866.22 & 82.90 & 272.70 & $3.89 \times 10^{-6}$ & 266.25 & 2.42 \\
\hline 1 & 125031.71 & 55.95 & 223.53 & $5.42 \times 10^{-6}$ & 215.99 & 3.49 \\
\hline 13 & 142793.57 & 65.11 & 234.35 & $3.83 \times 10^{-6}$ & 237.33 & -1.26 \\
\hline 5 & 150115.04 & 68.04 & 247.72 & $4.70 \times 10^{-6}$ & 240.92 & 2.82 \\
\hline 21 & 172134.57 & 79.52 & 261.18 & $3.23 \times 10^{-6}$ & 258.67 & 10.05 \\
\hline 9 & 168992.59 & 76.11 & 252.88 & $3.83 \times 10^{-6}$ & 256.46 & -1.40 \\
\hline
\end{tabular}

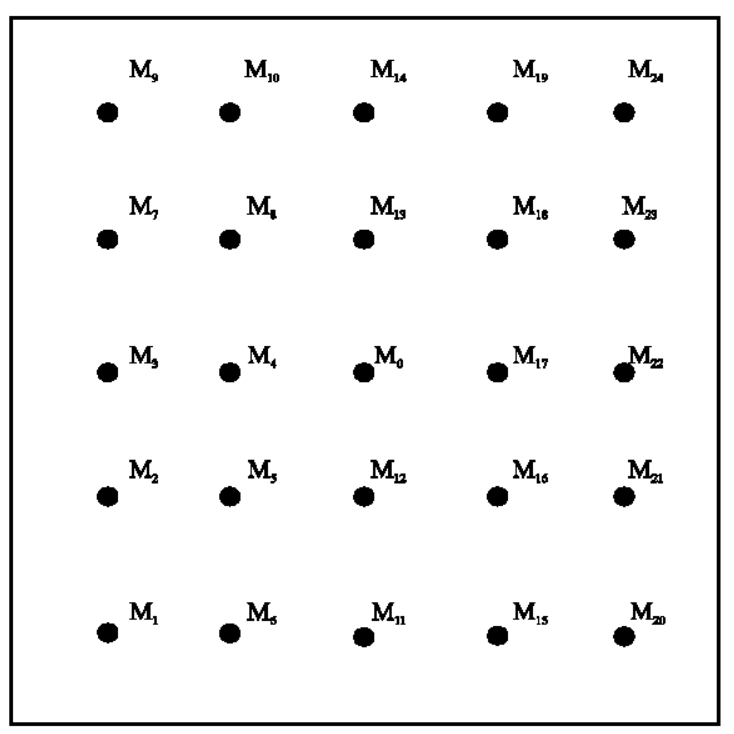

Fig. 11: Arrangement of collocation points for $\mathrm{N}=25$

$$
\mathrm{J}=\left(\mathrm{H}_{\mathrm{z}}-\mathrm{H}_{\mathrm{z}}^{*}\right)^{2}
$$

where, $\mathrm{H}_{z}^{*}, \mathrm{z}$-component of the magnetic field strength at which the elongation of the active element along the $0 y$ axis is maximized $\left(\Delta_{\mathrm{m}}\right)$. Applying the gradient method of descent, $i w_{c}^{(k)}$ it is determined in which:

$$
\mathrm{J} \leq\left(\varepsilon \mathrm{H}^{*}\right)^{2}
$$

where, ${ }^{\varepsilon}$ allowable relative error $\varepsilon=0.01$. It is advisable to take the dimensions of the section of the coil to reduce the dimensions of the systems $b_{1}=b_{2}=\sqrt{ }$ s where $\mathrm{S}=\mathrm{iw} / \mathrm{j} \mathrm{k}_{\mathrm{f}} \mathrm{j}$ is the current density, $\mathrm{k}_{\mathrm{f}}$ is the coefficient of the copper coils section filling $\mathrm{k}_{\mathrm{f}}=0.7$.

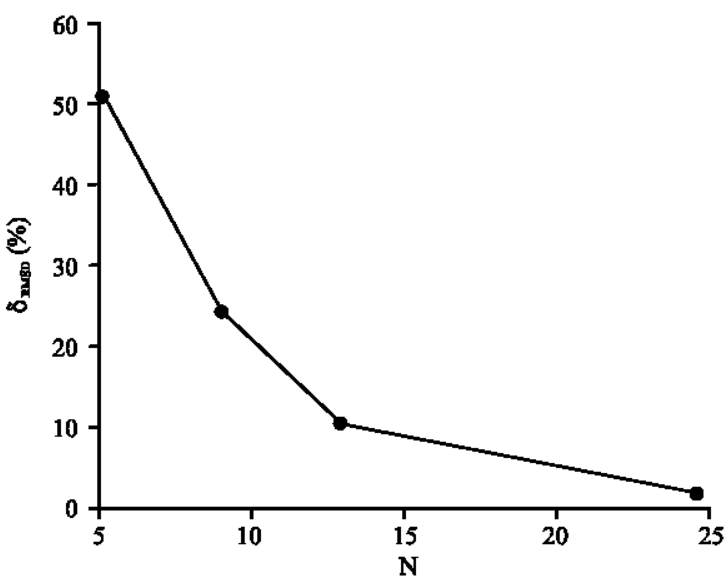

Fig. 12: Relative dependence of RMSD calculation of magnetic field on the number of field sources (magnetic moments)

For the research active elements of alloy $\mathrm{Ni}_{2} \mathrm{MnGa}$ in the form of parallelepipeds with a sizes $1 \times 2 \times 20 \mathrm{MM}$ manufactured by Adaptamat Inc. were used. For the selected there is $\mathrm{H}_{z}^{*}=370 \mathrm{kA} / \mathrm{m}$. Based on the preliminary calculations, ${ } \mathrm{w}_{\mathrm{c}}^{(0)}=4000 \mathrm{~A}$ is used. Applying the algorithm for solving the inverse problem to determine the required ampere turns of the coils at the iteration $n=7$ is obtained $\mathrm{iw}^{(7)}=10000 \mathrm{~A}$

\section{CONCLUSION}

The mathematical model of minimal dimension and an effective algorithm for calculating three-dimensional magnetic fields based on a combined finite element method and fundamental solutions are proposed. Moreover, vector point fictitious magnetic moments are used for the first time for the analysis of electromagnetic 
systems by the MFS. The new point sources of the field provide higher accuracy of calculation in comparison with magnetic dipoles. Numerical instability of solutions is not observed. The number of unknowns decreases by approximately 17 times in comparison with the FEM. In the absence of symmetry in the systems under investigation the scalar point sources, namely fictitious magnetic charges, magnetic dipoles and magnetic moments, provide the minimal dimension of the problem. The efficiency of the proposed algorithm also ensures the decomposition of the field in a linear subdomain into two fields: the field of coils with current and the magnetization field of the ferromagnet which allows moving to scalar variables instead of vector quantities. The obtained results allow effectively solving design problems, performing real-time diagnostics of positioning systems with active elements from the MSMA.

\section{ACKNOWLEDGEMENT}

The study results are obtained with the support of the project\#2.7193.2017/8.9 "Development of scientific bases of design identification and diagnosis systems for highly accurate positioning with application of the methodology of inverse problems of electrical engineering" carried out within the framework of the base part of state job.

\section{REFERENCES}

Asua, E., J. Feuchtwanger, A.G. Arribas, V. Etxebarria and I. Orue et al., 2009. Ferromagnetic shape memory alloy actuator for micro-and nano-positioning. Sens. Lett., 7: 348-350.

Bahvalov, Y.A., N.N. Gorbatenko, V.V. Grechikhin, 2014. Inverse Problems of Electrical Equipment. Magazine Russian Electromechanics, Novocherkassk, Russia, Pages: 211.

Bakhvalov, Y.A., V.V. Grechikhin and A.L. Yufanova, 2015. Mathematical modeling of magnetic fields by the combined method of fundamental solutions and finite elements in problems of diagnosis of systems with shape memory effect. Russ. Electromechanics, 6: 22-31.
Bakhvalov, Y.A., V.V. Grechikhin and A.L. Yufanova, 2016. The method of fundamental solutions using the vector magnetic dipoles for calculation of the magnetic fields in the diagnostic problems based on full-scale modelling experiment. Mater. Sci. Eng., 127: $1-10$.

Cao, C. and Q.H. Qin, 2015. Hybrid fundamental solution based finite element method: Theory and applications. Adv. Math. Phys., 2015: 1-38.

Chen, C.S., A. Karageorghis and Y.S. Smyrlis, 2008. The Method of Fundamental Solutions: A Meshless Method. Dynamic Publishers, Atlanta, Georgia, ISBN: 1890888-04-4, Pages: 329.

Gorbatenko, N.I., V.V. Grechikhin and D.V. Shaikhutdinov, 2015. Measuring and actuating devices based on shape memory ferromagnets. Met. Sci. Heat Treat., 56: 609-613.

Hubert, A., N. Calchand, Y.L. Gorrec and J.Y. Gauthier, 2012. Magnetic shape memory alloys as smart materials for micro-positioning devices. Adv. Electromagnet., 1: 75-84.

Riccardi, L., D. Naso, H. Janocha and B. Turchiano, 2012. A precise positioning actuator based on feedbackcontrolled magnetic shape memory alloys. Mechatron., 22: 568-576.

Shimoni, K., 1964. Theoretical Electrical Engineering. Mir Publishers, Moscow, Russia, Pages: 775.

Tozoni, O.V. and I.D. Maergoyz, 1974. Analysis of ThreeDimensional Electromagnetic Fields. Tekhnika Publisher, Kiew, Ukraine, Pages: 352.

Vasil'ev, A.N., V.D. Buchel'nikov, T. Takagi, V.V. Khovailo and E.I. Estrin, 2003. Shape memory ferromagnets. Phy.Usp., 46: 559-588.

Wang, F.X., W.J. Li, Q.X. Zhang, X.J. Wu and C. Ge, 2005. Design and control of linear actuators made by magnetically controlled shape memory alloy. Proceedings of the IEEE International Conference on Mechatronics (ICM'05), July10-12, 2005, IEEE, Taipei, Taiwan, ISBN:0-7803-8998-0, pp: 583-586.

Wilson, S.A., R.P. Jourdain, Q. Zhang, R.A. Dorey and C.R. Bowen et al., 2007. New materials for micro-scale sensors and actuators: An engineering review. Mater. Sci. Eng. R. Rep., 56: 1-129.

Yavorskiy, B.M. and A.A. Detlaf, 1974. Handbook of Physics for Engineers and University Students. Nauka Publishers, Moscow, Russia, Pages: 943. 